\title{
Effect of Egg Position in the Incubator on Broiler Hatching Results
}

http://dx.doi.org/10.1590/1806-9061-2019-1089

Original Article

-Author(s)

Boz MA' (iD https://orcid.org/0000-0002-7452-6895

Yozgat Bozok University, Department of Animal Science, Faculty of Agriculture, Yozgat 66135, Turkey.

\section{-Mail Address}

Corresponding author e-mail address Mehmet Akif Boz

Department of Animal Science, Faculty of Agriculture, Yozgat Bozok University,

Yozgat, 66135, Turkey.

Phone: +90 3542421096

Email: bozmakif@gmail.com

\section{- Keywords}

Incubator temperature, incubator position, hatchability, broiler hatching egg, embryonic mortalities.

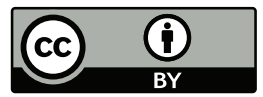

Submitted: 05/June/2019

Approved: 15/July/2019

\section{ABSTRACT}

This study investigated whether the effect of egg location during incubation on hatching results in broiler eggs. For this purpose, a total of 756 broiler eggs were incubated for 21 days. The eggs were divided near the door and near the fan, and distributed on top (216 eggs), 324 in the middle (324 eggs), and in the bottom (216 eggs) according to a completely randomized design (CRD). As a result of this study, no significant effect of egg location on incubation yield, hatchability, and embryonic mortalities was found ( $p>0.05)$. In some locations the eggs which were closer to the fan had generally higher hatchability (top fan $86.9 \%$, middle fan $69.6 \%$, and bottom fan $81.7 \%$ ). The value of the incubation yield was among 67.3-85.2\%. Embryonic mortalities were also analyzed according to the locations and were found as $0,00-2.57 \%$ for the early period, $0.00-1.00 \%$ for the middle period, $11.0-16.5 \%$ for the late period and $0.00-8.65 \%$ for pipped eggs. At different hatching times, the effect of the egg position on the hatching rate was found insignificant ( $p>0.05)$. The hatching rates support the result that temperatures measured in different locations of the machine were suitable for chick hatching. As a result, the effect of egg position in the machine was not statistically significant on the hatching results. However, the eggs closer to the fan had earlier hatching than the ones close to the door.

\section{INTRODUCTION}

The poultry sector has been growing for the last 50 years. Both broilers and layers have reached nearly maximum production capacities. There is also a negative relationship between live weight and reproductive performance of poultry that severely limits the ability of meat-type stocks to reproduce (Robinson \& Wilson, 1996). From now on, improvements are expected in hatching results, instead of production values. When all incubation conditions are optimum, healthy chicks hatch in approximately 21 days (Yalcin \& Siegel, 2003). Variation in incubation conditions affects embryo development, hatchability, and chick quality (Willemsen et al., 2010). Temperature is the most significant factor that controls embryo growth in incubation conditions (Meijerhof, 2000). The embryo cannot regulate its own temperature until hatching, so the incubator temperature is the only determinant to regulate the embryo's temperature (Leksrisompong et al., 2007). Incubation temperature also affects the hatchling's thermoregulatory ability, hormone levels, and post-hatching growth rate (Wilson, 1991; Decuypere, 1994). For proper embryo development, the temperature inside the hatching machine has to be homogenous. The optimum temperature for chickens has to be $37-38{ }^{\circ} \mathrm{C}$. Incubation duration shortens when the temperature is too high and delays when it is too low. But in both cases, hatchability and chick quality decrease. Chicks 
hatched in higher temperatures, often had unhealed navels and deformed toes (Deeming, 2000). Broiler performances are also negatively affected by improper incubation conditions (Meijerhof, 2003).

The temperature and humidity could not be homogeneous in all parts of the hatching machines. Temperature sensors are positioned on the inner top of the machines and thermostats regulate the temperature in these points. But the temperature of the location particularly away from the fans could be higher or lower. The aim of this study was to analyze the temperature and humidity fluctuations in different locations of the hatching machine and determine the effects of these fluctuations for broiler eggs on hatching results.

\section{MATERIAL AND METHODS}

This study was conducted at the Hatchery of the Ondokuz Mayis University Agricultural Faculty using a total of 756 eggs from Ross 308 breeders. Breeders were at 35 weeks of age. All eggs were laid on the same day and transferred to the hatchery. The eggs were placed in the incubation machine without previous storage. The incubation machine had 5 tiers with 2 trays capacity for each. The fan of the machine was located on the back side and for each tier, one tray is closer to the fan than the door side. The eggs were divided near the door and near the fan, and distributed on top (216 eggs), in the middle (324 eggs), and in the bottom (216 eggs) according to a completely randomized design (CRD). The temperature and humidity were set as $37.7^{\circ} \mathrm{C}$ and $60 \%$ in the incubation machine relatively. Automatic turning was applied to the eggs once every hour. The egg turning process was not done in the hatchery machine. The data loggers were located to the closest and farthest points to the fan of each tier. Temperature and relative humidity were recorded every 15 minutes during the incubation by the data loggers. The eggs were transferred to the hatching machine at the end of day 18. The design of the hatching machine (Cimuka T960/H) was similar to the incubation machine (Cimuka T960/S). The fan was located on the back side of the machine. The eggs were placed in the hatching baskets. Each hatching basket was placed in the same location as the tray in the incubation machine. Temperature and relative humidity were set as $37.5^{\circ} \mathrm{C}$ and $70 \%$ in the hatching machine, respectively. Data loggers were also placed to similar locations according to the fan. The numbers of hatched chicks were recorded at 528, 552 and 576 hours of incubation to determine whether related effects of hatching time with temperature and location in the machine occurred. All unhatched eggs were broken to identify embryonic development. The ratio of hatched chicks to fertilized eggs was determined as hatchability. Fertile eggs were determined by candling at the $18^{\text {th }}$ day. The fertility ratio was the ratio of fertile egg to total eggs placed to the incubator. Hatching rate is the ratio of hatched chicks to the fertile eggs and incubation yield is the ratio of hatched chicks to the total eggs (Yamak et al., 2010). At the end of incubation, unhatched eggs were individually broken, and embryonic mortalities were analyzed according to the growth of the embryos (Hamburger \& Hamilton, 1992). Early mortality was between the stages of 1-5 days, middle mortalities were between 6-14 days, late mortalities were between 15-21 days. Eggs which were broken by the chick and therefore did not hatch were evaluated as pipped eggs.

Statistical analysis was performed using the SPSS software program (version 20.0, licensed to Ondokuz Mayis University). Data expressed as percentages were subjected to arc-sine transformation; however, real values are given in the tables. Data generated from the study were subjected to analysis of variance (OneWay ANOVA) procedures for a CRD (completely randomized design) experimental model. Duncan's Multiple Range test were used to determine whether there are significant differences (95\%) between mean (egg position; top, middle, and bottom) values.

\section{RESULTS AND DISCUSSION}

Relative humidity and temperature records of different location in the incubation and hatching machine were given in Table 1 and Table 2. Changes in temperature and humidity were given in Figures 1, 2, 3 and 4 to understand the changes clearly in different locations. Hatching results of eggs according to the location in the incubation and hatching machine were given in Table 3. Fertility rates of the eggs were between $93.2 \%$ and $98.2 \%$ with a mean of $95.6 \%$ ( $p>0.05$ ). Hatchability of eggs ranged between $69.6 \%$ and $86.9 \%$ according to locations ( $p>0.05$ ). The mean hatchability was $76.6 \%$. Incubation yield was related to fertility and hatchability. The mean value of the incubation yield was $73.2 \%$. The temperature and humidity deviated from the setting value in different locations of the incubation machine. In all locations, the temperature increased with the growing embryo and mean temperature values were over $38^{\circ} \mathrm{C}$. This is in line with the finding of Mauldin \& Buhr (1995) who determined temperature was on average $1{ }^{\circ} \mathrm{C}$ warmer 
Table 1 - Temperature $\left({ }^{\circ} \mathrm{C}\right)$ and relative humidity (\%) values measured in different locations of the incubation machine in the first 18 days of embryo development.

\begin{tabular}{|c|c|c|c|c|c|c|c|c|c|c|c|c|}
\hline \multirow{3}{*}{ Day } & \multicolumn{4}{|c|}{ Top } & \multicolumn{4}{|c|}{ Middle } & \multicolumn{4}{|c|}{ Bottom } \\
\hline & \multicolumn{2}{|c|}{ Door } & \multicolumn{2}{|c|}{ Fan } & \multicolumn{2}{|c|}{ Door } & \multicolumn{2}{|c|}{ Fan } & \multicolumn{2}{|c|}{ Door } & \multicolumn{2}{|c|}{ Fan } \\
\hline & $\mathrm{T}$ & $\mathrm{H}$ & $\mathrm{T}$ & $\mathrm{H}$ & $T$ & $\mathrm{H}$ & $T$ & $\mathrm{H}$ & $\mathrm{T}$ & $\mathrm{H}$ & $\mathrm{T}$ & $\mathrm{H}$ \\
\hline 1 & 37.8 & 67.0 & 38.2 & 65.2 & 38.1 & 66.0 & 38.3 & 65.5 & 38.5 & 64.6 & 38.2 & 65.2 \\
\hline 2 & 37.7 & 63.7 & 38.2 & 62.0 & 37.9 & 63.2 & 38.2 & 62.3 & 38.3 & 61.9 & 38.1 & 62.2 \\
\hline 3 & 37.8 & 63.6 & 38.2 & 61.6 & 37.9 & 63.0 & 38.2 & 62.0 & 38.3 & 61.8 & 38.0 & 62.1 \\
\hline 4 & 37.8 & 63.6 & 38.3 & 61.6 & 38.1 & 63.0 & 38.3 & 62.0 & 38.5 & 62.0 & 38.0 & 62.1 \\
\hline 5 & 37.9 & 63.3 & 38.3 & 61.3 & 37.9 & 62.9 & 38.3 & 61.8 & 38.1 & 62.2 & 38.0 & 62.0 \\
\hline 6 & 37.9 & 63.4 & 38.3 & 61.5 & 37.8 & 63.3 & 38.2 & 62.0 & 38.1 & 62.6 & 38.0 & 62.3 \\
\hline 7 & 37.9 & 63.1 & 38.3 & 61.2 & 37.7 & 63.1 & 38.2 & 61.8 & 38.0 & 62.5 & 37.9 & 62.0 \\
\hline 8 & 37.9 & 63.1 & 38.3 & 61.0 & 37.7 & 63.0 & 38.2 & 61.6 & 38.1 & 62.1 & 38.0 & 61.9 \\
\hline 9 & 37.9 & 63.0 & 38.3 & 61.0 & 37.7 & 63.1 & 38.3 & 61.6 & 38.0 & 62.6 & 37.9 & 62.0 \\
\hline 10 & 37.9 & 62.0 & 38.4 & 60.0 & 37.9 & 61.7 & 38.4 & 60.1 & 38.1 & 61.1 & 38.1 & 60.6 \\
\hline 11 & 38.0 & 63.1 & 38.5 & 60.6 & 38.0 & 62.5 & 38.6 & 60.9 & 38.2 & 62.0 & 38.2 & 61.7 \\
\hline 12 & 38.1 & 62.6 & 38.6 & 60.1 & 38.1 & 62.0 & 38.8 & 60.1 & 38.3 & 61.6 & 38.2 & 61.2 \\
\hline 13 & 38.2 & 63.3 & 38.8 & 60.6 & 38.3 & 62.2 & 39.0 & 60.2 & 38.6 & 61.7 & 38.4 & 61.9 \\
\hline 14 & 38.3 & 63.6 & 39.0 & 60.7 & 38.6 & 61.8 & 39.3 & 60.0 & 38.9 & 61.5 & 38.6 & 61.8 \\
\hline 15 & 38.4 & 63.7 & 39.1 & 60.7 & 38.8 & 61.6 & 39.5 & 59.7 & 38.9 & 61.5 & 38.7 & 61.8 \\
\hline 16 & 38.4 & 63.6 & 39.1 & 60.5 & 38.9 & 61.4 & 39.6 & 59.5 & 39.0 & 61.4 & 38.8 & 61.6 \\
\hline 17 & 38.4 & 63.6 & 39.1 & 60.5 & 38.9 & 61.4 & 39.6 & 59.5 & 39.0 & 61.3 & 38.8 & 61.6 \\
\hline 18 & 38.4 & 63.7 & 39.1 & 60.6 & 38.9 & 61.5 & 39.6 & 59.5 & 39.0 & 61.5 & 38.8 & 61.7 \\
\hline Mean & 38.0 & 63.5 & 38.5 & 61.1 & 38.1 & 62.6 & 38.6 & 61,1 & 38,4 & 62,0 & 38.2 & 62.0 \\
\hline
\end{tabular}

T: Temperature, H: Relative humidity

inside the incubator than the controller. This increase is probably related to the design of the incubator. The design of the machine has an effect on the heat transfer between eggs and air inside incubation (French, 1997). If the air easily passes between the eggs and trays, the heat obtained from the embryo could move away. This would enable temperature

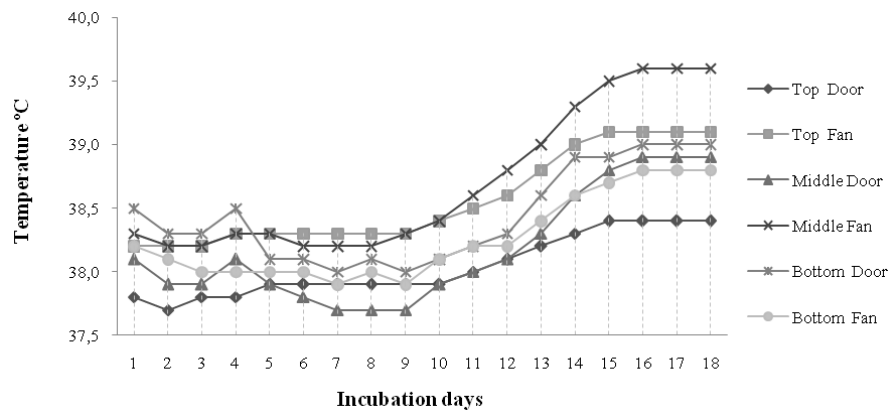

Figure 1 - Change of temperature at different location of the incubation machine.

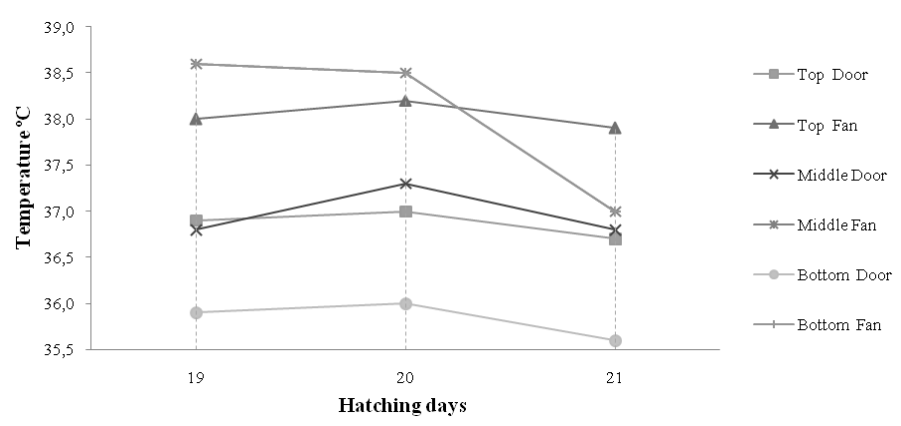

Figure 2 - Change of temperature at different location of the hatching machine. to keep stable in different parts of the incubator. The incubator fan speed is the most efficient factor in the air movement inside the incubator (Meijerhof \& van Beek, 1993). Hatchability is possible between the ranges of 35 to $40.5^{\circ} \mathrm{C}$ (Wilson, 1991). Despite the increased temperature, the values achieved in the current study were in these ranges.

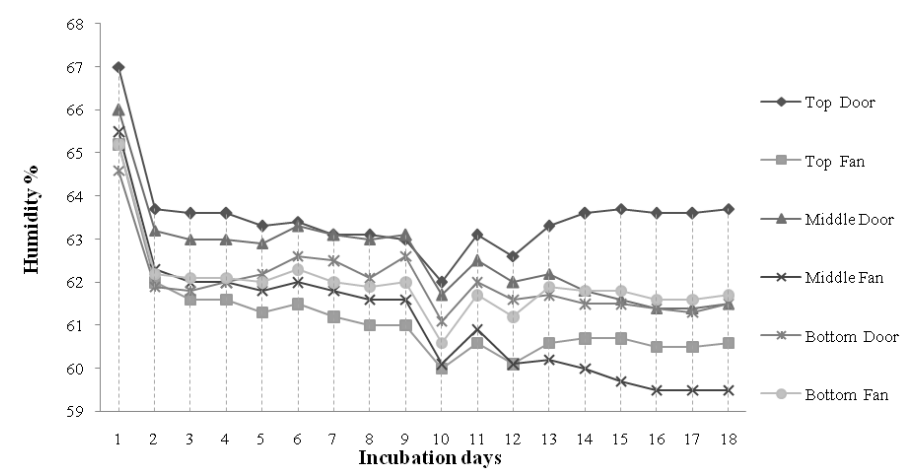

Figure 3 - Change of humidity at different locations of the incubation machine.

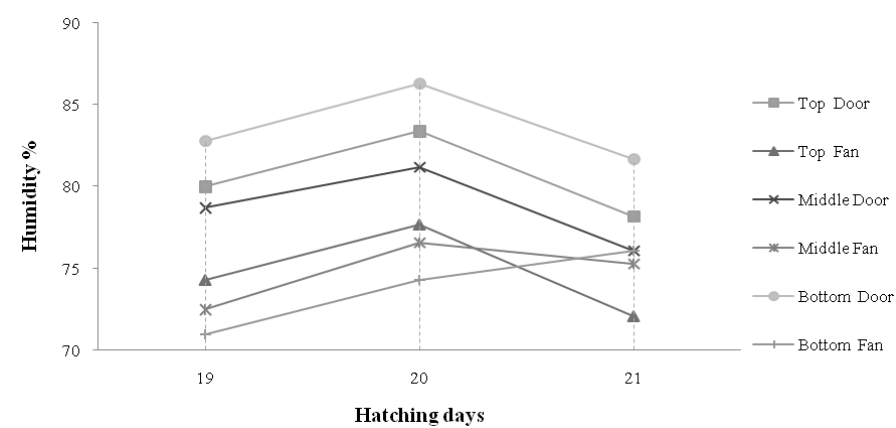

Figure 4 - Change of humidity at different location of the hatchingmachine. 
Table 2 - Temperature $\left({ }^{\circ} \mathrm{C}\right)$ and relative humidity (\%) values measured in different locations of the hatching machine in the last 3 days of embryo development.

\begin{tabular}{|c|c|c|c|c|c|c|c|c|c|c|c|c|}
\hline \multirow{3}{*}{ Day } & \multicolumn{4}{|c|}{ Top } & \multicolumn{4}{|c|}{ Middle } & \multicolumn{4}{|c|}{ Bottom } \\
\hline & \multicolumn{2}{|c|}{ Door } & \multicolumn{2}{|c|}{ Fan } & \multicolumn{2}{|c|}{ Door } & \multicolumn{2}{|c|}{ Fan } & \multicolumn{2}{|c|}{ Door } & \multicolumn{2}{|c|}{ Fan } \\
\hline & $T$ & $\mathrm{H}$ & $T$ & $\mathrm{H}$ & $T$ & $\mathrm{H}$ & $T$ & $\mathrm{H}$ & $T$ & $\mathrm{H}$ & $T$ & $\mathrm{H}$ \\
\hline 19 & 36.9 & 80.0 & 38.0 & 74.3 & 36.8 & 78.7 & 38.6 & 72.5 & 35.9 & 82.8 & 38.6 & 71.0 \\
\hline 20 & 37.0 & 83.4 & 38.2 & 77.7 & 37.3 & 81.2 & 38.5 & 76.6 & 36.0 & 86.3 & 38.5 & 74.3 \\
\hline 21 & 36.7 & 78.2 & 37.9 & 72.1 & 36.8 & 76.1 & 37.0 & 75.3 & 35.6 & 81.7 & 37.0 & 76.1 \\
\hline
\end{tabular}

T: Temperature, H: Relative humidity

The mean hatchability rate in the batch was $76.6 \%$. Different hatching rates obtained in different locations of the machine, but the differences were not significant. Conversely, Elibol \& Brake (2008) reported that eggs closer to the fan had approximately $5 \%$ higher hatchability. In our study, the distance to fan did not have an advantage or disadvantage on hatchability. In some locations the eggs which were closer to fan had higher hatchability but, in another location, thee ggs closer to the fan had lower hatchability. The hatching rates support the result that temperatures measured in different locations of the machine were suitable for chick hatching.

Embryonic mortalities were given in four stages. Mean ratios of early, middle and late period mortalities were as $0.86 \%, 0.60$ and $13.65 \%$, respectively ( $p>0.05$; Table 3). Embryonic mortalities were also analyzed according to the locations. The differences between embryonic mortalities at different locations were not significant (Table 3). But remarkable results were found in embryonic mortalities. The rates of late-period mortalities and pipped eggs were higher in all locations. This is the most critical period for the embryo and the mortality rate could increase up to $20 \%$ (Kuurman et al., 2003). Oxygen need for embryo increases during the late period of the incubation. Therefore, sufficient ventilation has to be supplied particularly in the hatching machine. Poor ventilation and improper humidity were reported as the main reasons for pipped eggs. Humidity values in the hatching machine were over $70 \%$ in all locations (Table 2). It is thought that the problem resulted from poor ventilation. Similar to the incubation machine, the design of the hatching machine restricted the air flow in the machine.

In the baskets located on top of the machine, 55.4\% of chicks hatched until 528 hours of incubation. In the middle of the machine, most of the eggs (63.5\%) hatched between 528 and 552 hours. Similarly, more than half of the eggs (53.5\%) located on the bottom of the machine hatched between 528 and 552 hours ( $p>0.05$; Table 4).

The eggs in the baskets which were closer to the fans, hatched earlier than the eggs closer to door, both in the top, middle and bottom of the machine. The rate of earlier hatched chicks was higher in the top location of the machine. Similarly, the eggs located closer to the fan hatched earlier than the eggs closer to the door of the machine. It is thought that this is about temperature. In all floors of the machine, mean of recorded temperature values in the parts closer to the fan were higher than the parts closer to the door. This temperature difference caused the chicks to hatch earlier in the parts which the temperature was higher.

It was difficult to provide a constant temperature in all points of the machine during incubation. This could be related to the design of the machine. The structure of the fan plays a significant role in the homogeny distribution of temperature and humidity. Another factor on the temperature increase is the metabolic

Table 3 - Hatching results (\%) of the eggs according to the location in the machine.

\begin{tabular}{|c|c|c|c|c|c|c|c|}
\hline \multirow{2}{*}{ Location } & \multirow{2}{*}{ Fertility } & \multirow{2}{*}{ Hatchability } & \multirow{2}{*}{ Incubation Yield } & \multicolumn{4}{|c|}{ Embryonic mortalities } \\
\hline & & & & Early & Middle & Late & Pipped \\
\hline Top door & 95.4 & 72.0 & 68.5 & 0.00 & 0.98 & 16.5 & 8.65 \\
\hline Top Fan & 98.2 & 86.9 & 85.2 & 0.96 & 0.00 & 12.2 & 0.00 \\
\hline Middle door & 93.2 & 76.3 & 71.0 & 0.65 & 0.68 & 13.2 & 4.60 \\
\hline Middle fan & 96.9 & 69.6 & 67.3 & 2.57 & 0.00 & 16.5 & 5.71 \\
\hline Bottom door & 93.5 & 73.2 & 68.5 & 0.00 & 1.00 & 11.0 & 6.96 \\
\hline Bottom fan & 96.3 & 81.7 & 78.7 & 0.96 & 0.96 & 12.5 & 3.85 \\
\hline Mean & 95.6 & 76.6 & 73.2 & 0.86 & 0.60 & 13.65 & 4.96 \\
\hline$p$ value & 0.118 & 0.665 & 0.473 & 0.171 & 0.769 & 0.957 & 0.645 \\
\hline SEM & 0.64 & 3.12 & 2.94 & 0.29 & 0.28 & 2.18 & 1.38 \\
\hline
\end{tabular}

SEM: Standard error of means 
Table 4 - Rate (\%) of hatched chicks at different incubation durations.

\begin{tabular}{|c|c|c|c|c|c|}
\hline \multirow[b]{2}{*}{ Location } & \multirow[b]{2}{*}{ Egg number } & \multirow[b]{2}{*}{ Chick number } & \multicolumn{3}{|c|}{ Ratio of hatched chicks according to hatching time } \\
\hline & & & $\begin{array}{c}\text { between } \\
504-528 \text { hrs }\end{array}$ & $\begin{array}{c}\text { between } \\
528-552 \text { hrs }\end{array}$ & $\begin{array}{c}\text { between } \\
552-576 \text { hrs }\end{array}$ \\
\hline Top door & 108 & 74 & 41.9 & 55.4 & 2.7 \\
\hline Top fan & 108 & 92 & 66.3 & 32.6 & 1.1 \\
\hline Top (Total) & 216 & 166 & 55.4 & 42.8 & 1.8 \\
\hline Middle door & 162 & 115 & 26.1 & 67.8 & 6.1 \\
\hline Middle fan & 162 & 119 & 28.0 & 58.9 & 13.1 \\
\hline Middle (Total) & 324 & 234 & 27.0 & 63.5 & 9.5 \\
\hline Bottom door & 108 & 74 & 29.7 & 55.4 & 14.9 \\
\hline Bottom fan & 108 & 85 & 44.7 & 51.8 & 3.5 \\
\hline Bottom (Total) & 216 & 159 & 37.7 & 53.5 & 8.8 \\
\hline$p$ value & & & 0.522 & 0.712 & 0.295 \\
\hline SEM & & & 6.52 & 5.62 & 2.12 \\
\hline
\end{tabular}

SEM: Standard error of means

heat production of the embryos. On the other hand, for successful hatching, the eggshell temperature is more important than the determined temperature in the machine. Most of the previous studies showed that the temperature within the incubator can differ between 0.4 and $3.0^{\circ} \mathrm{C}$ from the setpoint temperature and the design of the machine is the main factor and these deviations (Mauldin \& Buhr, 1995; French, 1997; 2001).

\section{CONCLUSION}

As a result, the location of the egg inside the machine did not significantly affect hatching results in this study. However, temperature and humidity values may vary in different locations. The temperature values obtained in this study were in the ranges that embryo could tolerate and hatch successfully. Higher temperatures could affect the total duration of incubation. Eggs located closer to fan hatched earlier than the eggs located closer to the door. Chick quality and broiler performances according to egg location during incubation have to be investigated in further studies.

\section{REFERENCES}

Decuypere E. Incubation temperature and postnatal development. Proceedings of 9th European Poultry Conference; 1994; Glasgow: World's Poultry Science Association; 1994. p.407-410.

Deeming DC. Are you overheating your eggs without realizing it? World Poultry 2000;34-35.

Elibol O, Brake J. Effect of egg weight and position relative to incubator fan on broiler hatchability and chick quality. Poultry Science 2008;87:19131918.

French NA. Modeling incubation temperature: the effects of incubator design, embryonic development, and egg size. Poultry Science 1997;76:124-133.
French NA. Temperatures in a tunnel incubator-A long term study. Avian Poultry Biology Reviews 2001;12:184-186.

Hamburger V, Hamilto, H L. A series of normal stages in the development of the chick embryo. Developmental Dynamics 1992;195(4):231-272.

Kuurman WW, Bailey BA, Koops WJ, Grossman M. A model for failure of a chicken embryo to survive incubation. Poultry Science 2003;82:214222.

Leksrisompong L, Romero-Sanchez H, Plumstead PW, Brannan KE, Brake J. Broiler incubation. 1. effect of elevated temperature during late incubation on body weight and organs of chicks. Poultry Science 2007:86:2685-2691.

Mauldin JM, Buhr RJ. What is really happening in your incubator? International Hatchery Practice 1995;9(5):19-22.

Meijerhof R, Beek $G$ van. Mathematical modelling of temperature and moisture loss of hatching eggs. Journal of Theoretical Biology 1993;165:27- 41.

Meijerhof R. Embryo temperature as a tool in the incubation process [WPSA Working Group, 6]. Oxford: St. Edmand's Hall; 2000.

Meijerhof R. Problem solving in the commercial broiler sector. Incubation and fertility research group meeting. Avian and Poultry Biology Reviews 2003;14: 212-214.

Robinson FE, Wilson JL. Reproductive failure in overweight male and female broiler breeders. Animal Feed Science and Technology, 1996;58:143150.

Willemsen H, Kamers B, Dahlke F, Han H, Song Z, Ansari Pirsaraei Z, et al. High and low-temperature manipulation during late incubation: Effects on embryonic development, the hatching process, and metabolism in broilers. Poultry Science 2010;89:2678-2690.

Wilson HR. Physiological requirements of the developing embryo: Temperature and turning. In: Tullett SG, editor. Avian incubation. London: Butterworth-Heinemann; 1991. p.145-156.

Yalcin S, Siegel PB. Exposure to cold and heat during incubation on developmental stability of broiler embryos. Poultry Science 2003;82:1388-1392.

Yamak US, Sarica M, Boz MA. Hatching results of genotypes with different live weights used for developing slow growing meat type chickens. Avian Biology Research 2010;3(3):123-143. 
